\title{
Demonstration of bone marrow derived cells in synovial lining by means of giant intracellular granules as genetic markers
}

\author{
J. C. W. EDWARDS AND D. A. WILLOUGHBY \\ From the Department of Rheumatology and Experimental Pathology, St Bartholomew's Hospital, \\ London EC1
}

SUMMARY Beige mice carry a gene (bg) which codes for the presence of giant intracellular granules in a variety of cell types. Bone marrow from beige mice was transplanted into irradiated normal mice. Giant granules similar to those seen in beige mouse synovial cells were observed subsequently in the synovial lining cells of marrow recipients, indicating an influx of bone marrow derived cells into the synovial lining. Giant granule bearing cells also appeared in the subintima. On electron microscopy giant granules have been demonstrated only in macrophage-like or type A cells in marrow recipient synovia, despite the occurrence of giant granules in both type A and type $\mathrm{B}$ lining cells in donor material (beige). This tends to suggest that only the type A lining cells are derived from bone marrow, as might be expected from their similarity to mononuclear phagocytes elsewhere. However, the possibility remains that type B cells are also derived from bone marrow but have a slower rate of replacement.

It has been suggested that some or all of the cells in the synovial lining are replaced throughout life by mononuclear phagocytes arising in the bone marrow and reaching the tissues as blood borne monocytes. ${ }^{1}$ Type A synovial lining cells are morphologically similar to mononuclear phagocytes elsewhere. ${ }^{2}$ The argument for their derivation from bone marrow stem cells is correspondingly that much stronger than for the type B cells, which are more similar to fibroblasts. The purpose of the present study was to assess the contribution of bone marrow derived cells to the synovial lining cells of both types by means of the transplantation of marked bone marrow cells.

The beige mouse is homozygous for the recessive beige gene (bg) which codes for the presence of abnormally large granules, thought to be of lysosomal origin, in a variety of cell types. ${ }^{3}$ These giant granules have proved to be useful genetic markers for tracing cell lines related to the mononuclear phagocyte system, including osteoclasts, ${ }^{4}$ and mesangial mononuclear phagocytes. ${ }^{5}$ An initial light and electron microscopic study was undertaken to establish the presence of such granules in synovial lining

Accepted for publication 22 October 1980.

Correspondence to Dr J. C. W. Edwards, St Bartholomew's Hospital Medical College, West Smithfield, London EC1 A 7BE. cells. Its having been established, normal mice were irradiated and then grafted with bone marrow aspirate from beige mice. The synovial lining was examined for the appearance of giant granule bearing cells indicating the replacement of lining cells from bone marrow.

\section{Materials and methods}

Mouse stock. Mice were obtained from Dr J. Loutit at the MRC Radiobiology Unit at Harwell. Beige mice belonged to a colony into which the beige gene had been introduced from the Jackson Laboratory in 1963. ${ }^{4}$ Normal mice were derived from a brown strain which was closely histocompatible.

Irradiation was carried out with a linear electron accelerator. Dosages of 400 to 1000 rads were used in an initial study of marrow sensitivity, rates of recipient marrow regeneration, and deaths despite marrow replacement. A dose of 850 rads was selected as being effective in suppressing bone marrow with minimal regeneration of recipient marrow over 3 weeks and minimal death rate despite marrow replacement.

Bone marrow transplantation was performed within 6 hours of irradiation. Marrow donors were killed by cervical dislocation and the ilia, femora, and tibiae dissected out. Marrow was expelled into 
Hanks's balanced salt solution with a 25 gauge needle. The aspirate was washed once and made up to $0.3 \mathrm{ml}$ in Hanks's balanced salt solution. A cell count was performed to ensure that all recipient mice received at least $10^{7}$ nucleated cells. $0.1 \mathrm{ml}$ aliquots of aspirate were injected into the tail veins of either 2 or 3 irradiated mice per donor under ether anaesthesia.

Graft viability assessment. Bone marrow graft viability was assessed both in the initial radiation dosage study and at 8-10 days and again at the time of killing for mice used for synovial histology. Assessment was made by taking a blood smear from a tail vein and staining with Sudan black B. Beige neutrophils were identifiable by the presence of few very large sudanophilic granules. The presence of such beige neutrophils in the circulation was taken as evidence of graft survival. Regeneration of recipient marrow was also assessed by the reappearance of normal neutrophils.

Harvesting of peritoneal cells. Peritoneal cells were studied from beige mice, normal mice, and bone marrow recipient mice to check the viability of the method for mononuclear phagocytes. Cells were harvested by irrigating the peritoneal cavity with $3 \mathrm{ml}$ of Hanks's solution, agitating for 3 minutes, and aspirating the resulting cell suspension. This was centrifuged to produce pellets for embedding in resin for microscopy.

Synovectomy. Synovectomy was collected by anterior synovectomy of the knee under an Olympus dissecting microscope. The fibrous capsule, patellar tendon, and quadriceps muscle were raised and cut away together with the patella. The remaining annulus of synovial membrane, including the infrapatellar fat pad, was then teased off the bone and prepared for electron and light microscopy. During the dissection the tissues were bathed in glutaraldehyde in sodium cacodylate buffer.

Fixation and embedding of tissues. Tissue for both light and electron microscopy was processed similarly as follows: initial fixation in glutaraldehyde in sodium cacodylate buffer for 1 hour, overnight was in cacodylate sucrose buffer, postfixation in osmium tetroxide for 1 hour, 10-minute wash in cacodylate sucrose buffer, staining in saturated aqueous uranyl acetate for 1 hour, dehydration with $70 \%, 90 \%$, and absolute ethanol, infiltration with Araldite and propylene oxide for half an hour, followed by 2 changes of fresh Araldite over at least 24 hours and final polymerisation in Araldite at $70^{\circ} \mathrm{C}$.

Light microscopy. Sections for light microscopy were cut on an ultramicrotome at about $0.5 \mu \mathrm{m}$ thickness. Sections were stained with hot aqueous toluidine blue until nuclei stained deep blue-violet and fat stained sky blue. Sections were viewed under oil immersion at a total magnification of 1000 times. A linear scale was incorporated into the eyepiece.

Giant granules were identified in light microscope sections by the following criteria: (1) dark blue staining (not blue-violet); (2) presence within lining cell cytoplasm and discontinuity on serial sections from nuclear material; (3) at least 1 diameter greater than $1 \mu \mathrm{m}$; (4) presence on at least 2 serial sections; (5) perfect circular or elliptical outline except for very large $(3 \mu \mathrm{m})$ compound granules.

Light electron microscopy. A few sections were viewed under the ISI prototype light electron microscope (LEM) to establish that giant granules identified on light microscopy corresponded to those seen with the conventional electron microscope.

Electron microscopy. Sections for electron microscopy were stained with lead citrate and viewed under a Hitachi electron microscope. Granular structures exceeding $1 \mu \mathrm{m}$ in diameter with electron-dense contents were identified and photographed, particular attention being paid to the nature of the surrounding cytoplasm, whether of A or B cell type.

\section{Results}

LIGHT AND ELECTRON MICROSCOPIC APPEARANCES OF NORMAL AND BEIGE SYNOVIUM

In $0.5 \mu \mathrm{m}$ resin sections stained with toluidine blue normal mouse synovium resembled a scaled down version of human synovium. The lining layer was mostly 2 or 3 cells deep, and the subintima was in places reduced to a few bundles of collagen and the occasional blood vessel. At other sites a more substantial subintima contained variable numbers of fat cells together with scattered mast cells and other mononuclear cells, blood vessels, and occasional nerves. The lining cells were similar to those seen in human tissue, and some features of $\mathrm{A}$ and $\mathrm{B}$ types could be distinguished. In particular, some cells showed marked vacuolation and lamellation of the surface (type A).

Darkly staining granules occurred in normal synovium, both in vacuolated and nonvacuolated cells. They were generally less than $0.5 \mu \mathrm{m}$ in diameter, though isolated granules were seen up to about $0.7 \mu \mathrm{m}$. No darkly staining granules of $1 \mu \mathrm{m}$ diameter conforming to the above criteria (see method) were seen in normal tissue. Pale blue granules of similar colour to surrounding fat and greater than $1 \mu \mathrm{m}$ in diameter were seen on five occasions. These were up to $20 \mu \mathrm{m}$ across and were considered to represent immature adipocyte fat inclusions. Groups of blue violet granules filling the cytoplasm of cells just deep to the intimal layer and in the subintima were considered to represent mast cell granules. These often 


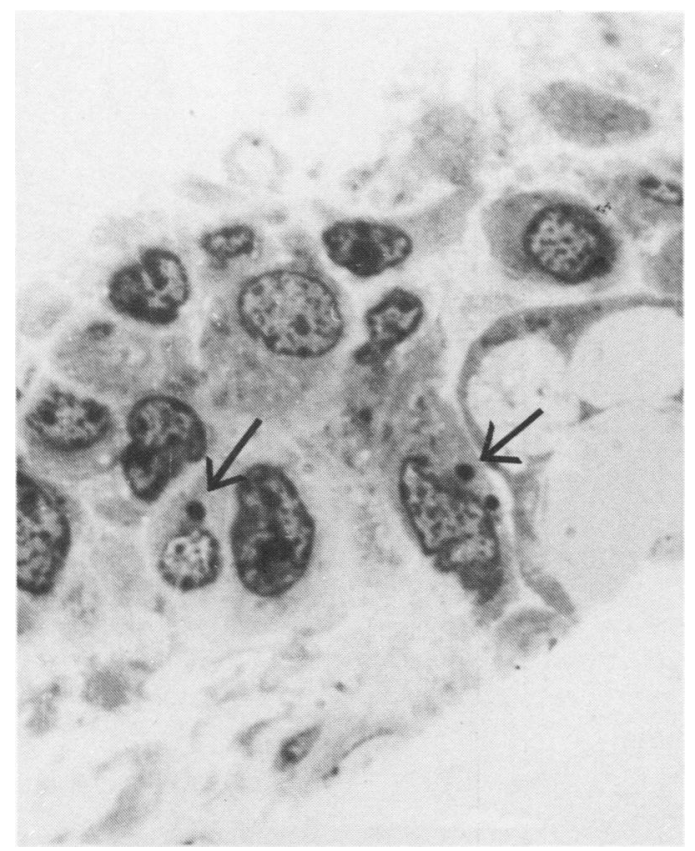

Fig. 1 Semithin resin section of beige mouse synovium stained with toluidine blue. Giant granules are arrowed. (Light micrograph, $\times 1300$ ). exceeded $1 \mu \mathrm{m}$ in diameter but were easily identified by their colour variable depth of staining, and close packed arrangement.

Beige mouse synovium appeared identical to normal tissue except for the presence of much larger darkly staining granules both in lining cells and in subintimal mononuclear cells (Fig. 1). About 1 cell in 10 on any $0.5 \mu \mathrm{m}$ section showed a granule of over 1 $\mu \mathrm{m}$ diameter. Granules were generally 1-2 $\mu \mathrm{m}$ across but ranged up to greater than $3 \mu \mathrm{m}$. Cells often contained a single granule, but up to 6 were seen in 1 cell. Many granules showed darkest staining at the periphery, and the largest granules were clearly compound, giving a marbled appearance. Mast cells were clearly distinguishable by enormous blue violet granules of 5 or more $\mu \mathrm{m}$ diameter. Sections of pellets of peritoneal macrophages from normal and beige mice showed a very similar difference in granule size, though the giant granules in peritoneal cells tended to be more irregular.

Under the electron microscope mouse synovial lining cells appeared similar to human lining cells. Types $A$ and $B$ could be distinguished, the latter being in the majority in a ratio of between about 10:1 and $4: 1$ as far as could be judged from single sections. Not all cells could be typed with certainty, but the majority of cells that were well visualised were clearly

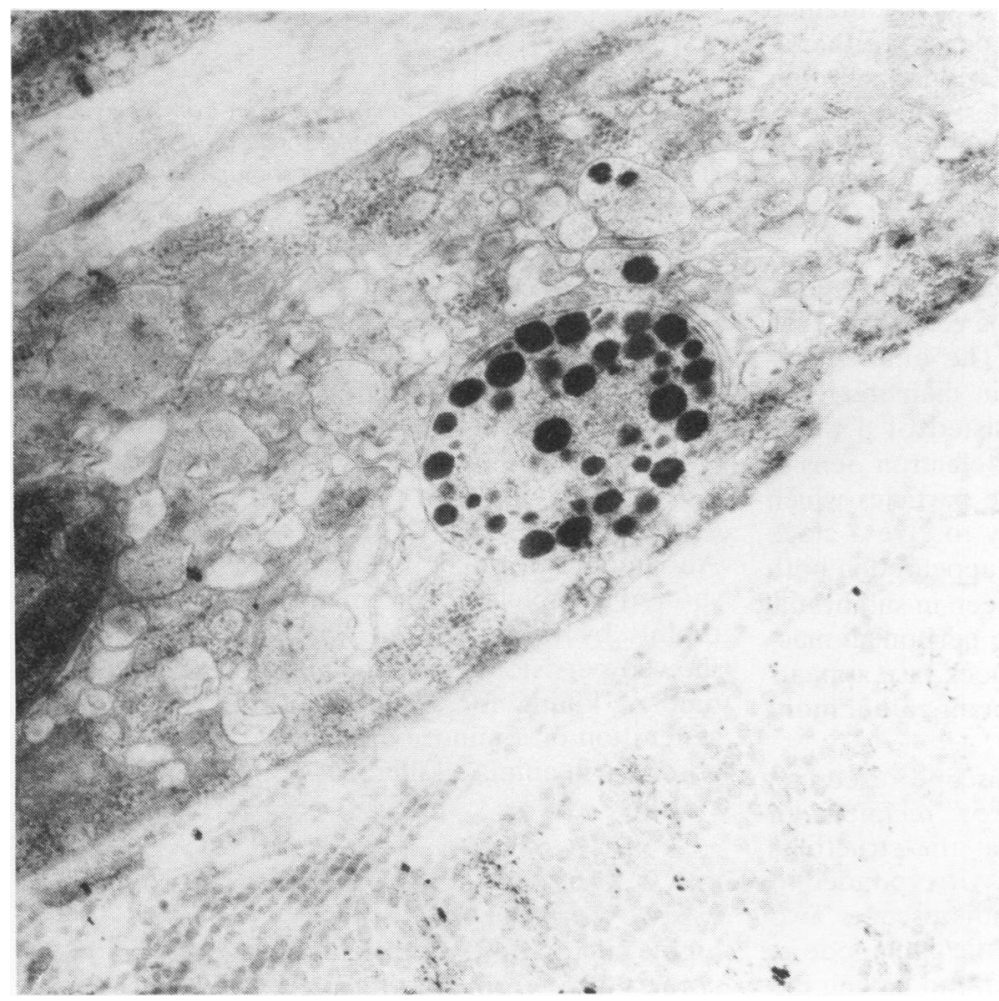

Fig. 2 Electron micrograph of a beige synovial lining cell containing a giant granule. $(\times 27825)$. 


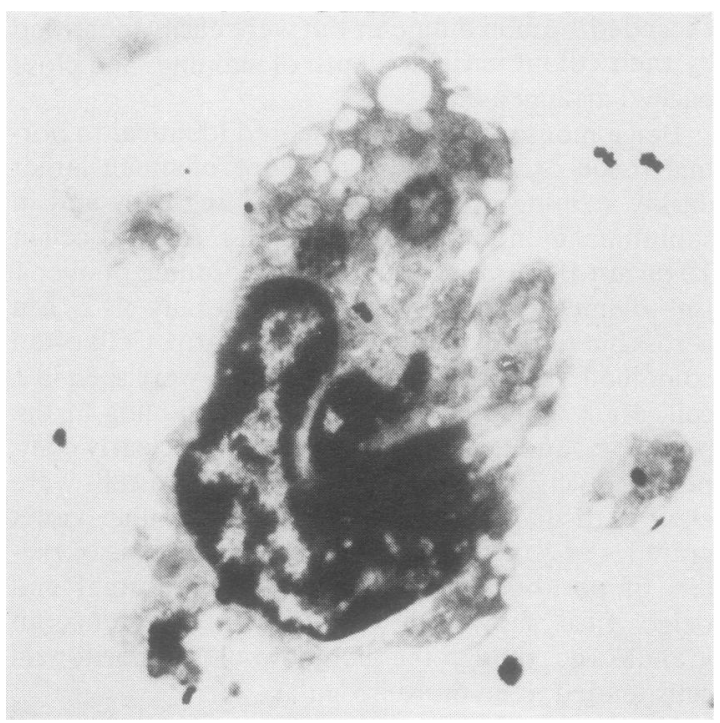

Fig. 3 Light-electron microscope picture in EM mode showing a cell with 2 giant granules from a beige bone marrow transplant recipient. Note the electron dense particles within the outer membrane. These granules were initially identified in the light mode as staining dark blue with toluidine blue. $(\times 5440)$.

one type or the other. Both types of cell contained granular structures of high electron density, either as single granules or in collections within an outer membrane. Such outer membranes were usually $0 \cdot 3-0.4 \mu \mathrm{m}$ across, occasionally being larger. The largest observed was $0.7 \mu \mathrm{m}$ across. These structures were considered to represent various forms of lysosome.

Beige synovium contained a similar cell population, but much larger collections of electron dense particles were observed (Fig. 2). The outer membrane frequently exceeded $1 \mu \mathrm{m}$ in diameter. The contents of such membranes consisted of a finely granular matrix of medium to low electron density dotted with strongly electron dense particles which tended to be arranged peripherally to give a clock face appearance. These collections appeared in both cell types. Similar structures were seen in subintimal mononuclear cells and also in beige peritoneal macrophages, though in the latter the clock face appearance was not evident, the contents being rather more heterogeneous.

With the light electron microscope used on synovium from a beige bone marrow recipient an attempt was made to establish that the structures described with the light microscope corresponded to those described under the electron microscope. Two giant granules were identified under the light mode as being greater than $1 \mu \mathrm{m}$ in diameter and having the

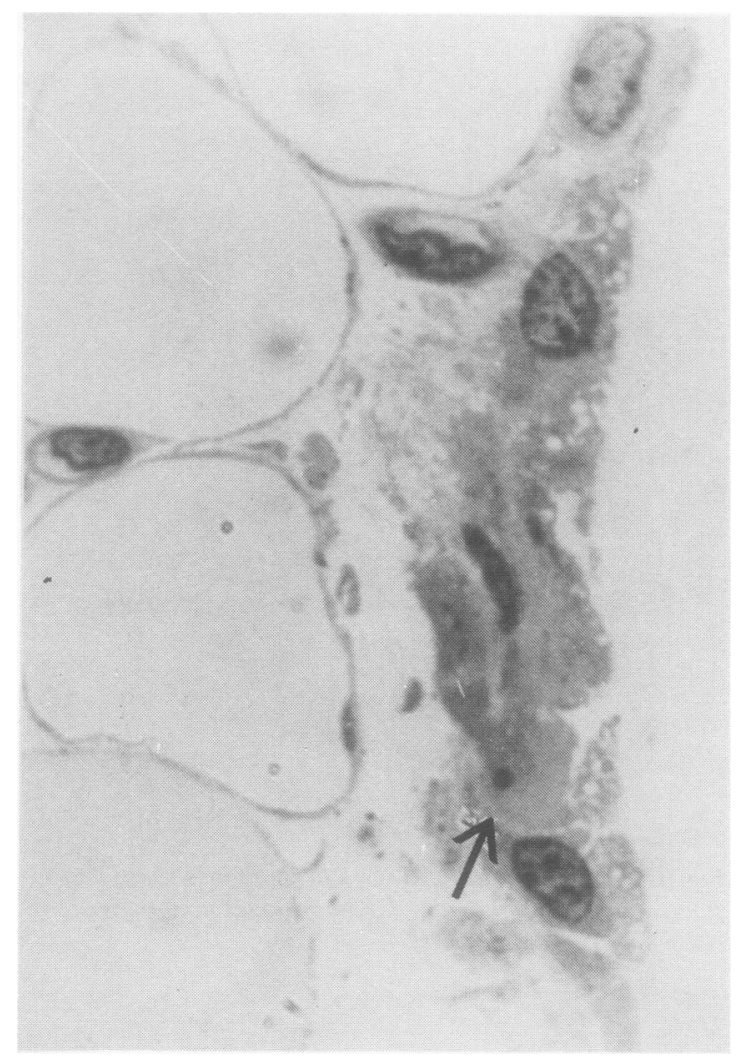

Fig. 4 Semithin resin section of synovium from a beige bone marrow transplant recipient stained with toluidine blue. $A$ giant granule is arrowed. (Light micrograph $\times 1330)$.

characteristic peripheral dark staining with toluidine blue. These were then viewed under the transmission EM mode and photographed. The electron microscopic appearance was typical of the lysosomal structures described above, the peripheral toluidine blue staining corresponding to the clock face distribution of the electron dense particles (Fig. 3).

\section{GRAFT VIABILITY ASSESSMENTS}

All animals receiving beige bone marrow grafts showed complete replacement of circulating neutrophils by beige cells at 8-10 days. All animals showed persistence of circulating beige cells at the time of killing for synovial histology, though regeneration of a minority of normal neutrophils was observed in animals killed 51, 60, and 66 days after grafting.

EXAMINATION OF SYNOVIUM FROM BONE MARROW GRAFT RECIPIENTS

Light microscopy revealed giant granules in all synovia taken from graft recipients. Numbers tended 


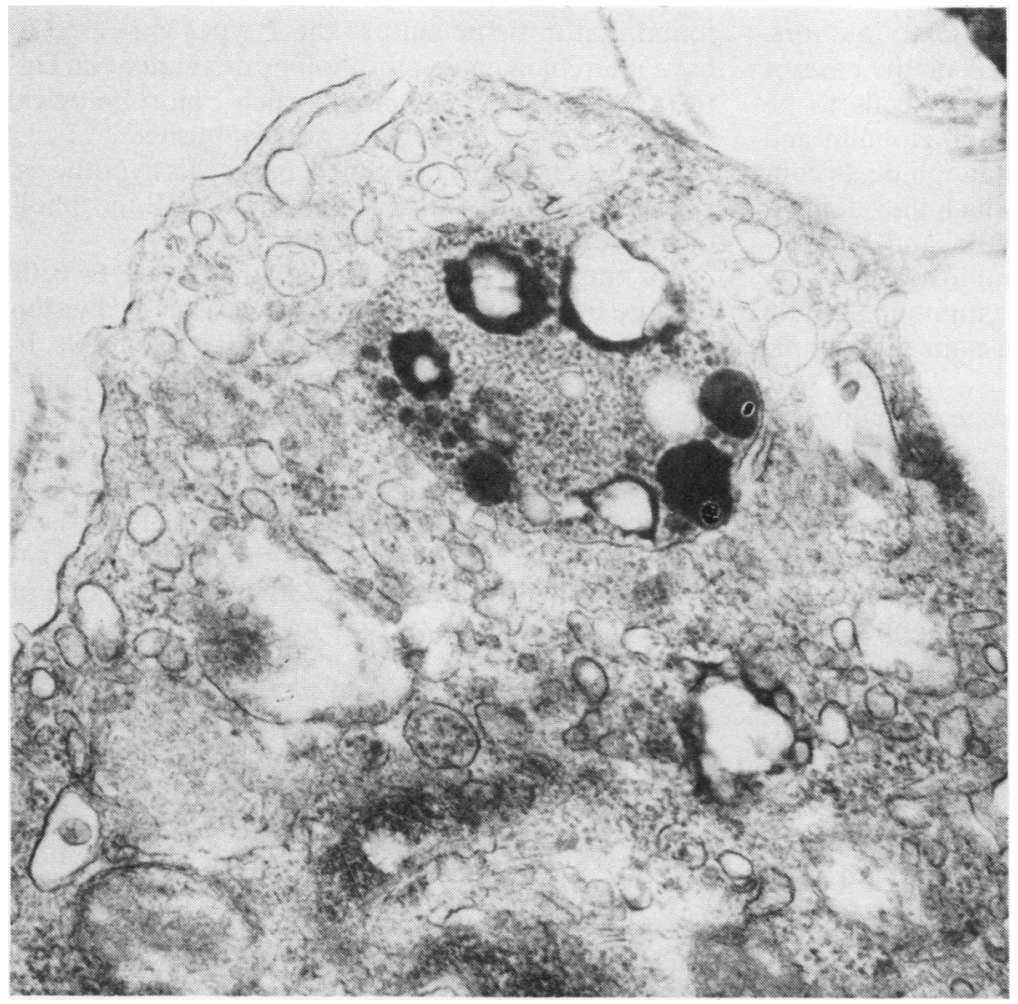

Fig. 5 Electron micrograph of a synovial lining cell from a beige bone marrow transplant recipient. A giant granule containing electron dense particles is present. The cell is oftype A morphology. ( $\times 27$ 430).

to increase with time after transplantation, but there was considerable variation. Giant granules were often but not always, seen in areas of vacuolation and lamellation. Counts were made of the number of giant granules per 1000 cross-sections of nuclei (see Fig. 4 and Table 1).

Electron microscopy of synovia from beige bone marrow recipients has revealed giant granules only in type A cells, that is to say cells with minimal rough endoplasmic reticulum, prominent vacuolation, and lamellation of the cell membrane (Fig. 5). Approxi-

Table 1 Numbers of giant granules seen in semithin resin sections containing 1000 nucleated synovial lining cells (per animal)

\begin{tabular}{lcc}
\hline Animal & & $\begin{array}{l}\text { Giant granules per } \\
1000 \text { lining cells }\end{array}$ \\
\hline Normal 1 & & 0 \\
Normal 2 & & 0 \\
Normal 3 & 0 \\
Beige & 87 \\
Beige bone marrow recipients; & \\
20 days post transplantation & 11 \\
23 & $"$ & 15 \\
30 & $"$ & 44 \\
36 & $"$ & 26 \\
44 & $"$ & 17 \\
51 & $"$ & 75 \\
60 & $"$ & 19 \\
66 & & 60 \\
\hline
\end{tabular}

mately 450 cells have been examined. Similar giant granules were present both in subintimal mononuclear cells and in peritoneal macrophages taken from bone marrow recipients.

\section{Discussion}

Evidence is presented for the replacement of synovial lining cells from the bone marrow in the adult mouse. It seems likely that the mode of replacement is similar in man. The contribution of bone marrow derived cells appears to be substantial. Considerable variation in the numbers of giant granules recorded in transplant recipient synovia was noted, probably relating to the very variable ratio of type $A$ and type $B$ cells in different areas and the tendency for giant granules to occur in groups. In view of this and the possible changes in cell maturity and metabolism in a postirradiation population it is not possible on the basis of granule numbers alone to establish whether one or both types of cell are bone marrow derived. However, electron microscopy on approximately 450 cells in transplant recipient synovial lining has revealed giant granules only in type A cells, suggesting that only this cell type is bone marrow derived.

A distinction has been made between bone marrow derived mononuclear phagocytes and type $\mathrm{A}$ 
cells in synovial preparations by some authors. Traycoff et al. ${ }^{6}$ separated the 2 largely on the basis of sudanophilia. They considered type A cells to be largely or wholly negative for immunoglobulin and complement receptors, and nonsudanophilic, in contrast to mononuclear phagocytes, which they defined as sudanophilic and immunoglobulin and complement receptor positive. Theofilopoulos et al. ${ }^{7}$ however, considered type A cells to be immunoglobulin and complement receptor positive nonsudanophilic cells.

Barratt et al. ${ }^{1}$ confirmed the presence of numerous immunoglobulin and complement receptor bearing cells in the lining layer by a careful trypsinisation of this layer alone. It is of note that in the present study comparable numbers of bone marrow derived cells were found in the subintimal and lining layers. This may explain why confusion has arisen among studies using whole minced synovium, where lining cells would be heavily contaminated with subintimal mononuclear phagocytes and other cells. Clearly a method such as that of Barratt et al. ${ }^{1}$ is essential for meaningful study of lining cells in suspension.

Having demonstrated in this study that a significant proportion of synovial lining cells with macrophage morphology are bone marrow derived it seems difficult to justify the suggestion that a second macrophage-like type of cell, which is not bone marrow derived and may or may not have surface receptors for immunoglobulin and complement, coexists in the lining layer. The simpler suggestion that all type A cells are bone marrow derived is far more satisfactory. The apparent nonsudanophilia of these cells may relate to a local maturation process or simply to their metabolic activity in this site. Whether the bone marrow stem cells for type $A$ are the same as those for other mononuclear phagocytes remains open to speculation.

The origin of the type B cells remains unclear. It is easy to assume that it is replaced by local reduplication. This would be consistent with the findings of Coulton et al., ${ }^{8}$ who demonstrated DNA levels in lining cells consistent with a slowly reduplicating population. However, Barratt et al. ${ }^{1}$ argued that both types of lining cell are bone marrow derived. They found that in tissue culture the 2 types appeared to have interchangeable morphology dependent on culture conditions. Whether such morphological changes can occur in vivo is not established.

The present study does not support this hypothesis, but the possibility remains that the type $\mathrm{B}$ morphology develops very slowly in vivo.

An alternative possibility is that type B cells migrate into the lining layer having arisen by division of subintimal fibroblasts or other tissue fixed cells. In this model the lining would be seen as a largely nondividing cell layer fed both from the blood stream (type A) and the near-by tissue (type B) much in the way that the wall of a granuloma cavity develops. This would explain the remarkable rarity of mitosis in synovial lining, ${ }^{8}$ but would not totally preclude occasional cell division as described in the maintenance of a chronic granuloma by Spector and Lykke. ${ }^{9}$

We thank Dr J. F. Loutit and Dr T. J. Chambers for their help in setting up this study, Dr J. Lovell for providing facilities for irradiation, Dr J. F. Loutit for providing the beige mice, and Mrs G. Carson and Mr S. Jones for technical assistance. Dr J. C. W. Edwards is supported by a Muir Hambro fellowship appointed by the Royal College of Physicians (UK), and this financial support is gratefully acknowledged.

\section{References}

${ }^{1}$ Barratt M E J, Fell H B, Coombs R R A, Glauert A M. The pig synovium II. J. Anat 1977; 123: 47-66.

2 Van Furth R. Mononuclear phagocytes in inflammation. In: Vane R, Ferreira S H eds. Inflammation: Handbook of Experimental Pharmacology. Springer Berlin, Heidelberg, New York: Springer, 1978: 50/1.

${ }^{3}$ Lutzner M A, Lowrie C T, Jordan H W. Giant granules in leucocytes of beige mice. J Hered 1967; 58: 299.

${ }^{4}$ Ash P, Loutit J F, Townsend K M S. Giant lysosomes, a cytoplasmic marker in osteoclasts of beige mice. J Pathol in press.

${ }^{5}$ Striker G E, Mannik M, Tung M Y. Role of marrow derived monocytes and mesangial cells in removal of immune complexes from renal glomeruli. J Exp Med 1979; 149: 127-36.

${ }^{6}$ Traycoff R B, Pascual E, Schumacher H R. Mononuclear cells in human synovial fluid. Arthritis Rheum 1976; 19: 743-8.

'Theofilopoulos A N, Carson D A, Tavassoli M, et al. Evidence for the presence of receptors for $\mathrm{C} 3$ and $\mathrm{IgG} \mathrm{Fc}$ on human synovial cells. Arthritis Rheum 1980; 23 : 1-9.

${ }^{8}$ Coulton L A, Henderson B, Bitensky L, Chayen J. DNA synthesis in human rheumatoid and non-rheumatoid synovial lining. Ann Rheum Dis 1980; 39: 241-7.

- Spector W G, Lykke A W J. The cellular evolution of inflammatory granulomata. J Pathol Bacteriol 1966; 92: 163-77. 